\section{Role of Hydrogen Peroxide in the Neutrophil-mediated Release of Prostacyclin from Cultured Endothelial Cells}

John M. Harlan and Karleen S. Callahan

Department of Medicine, Hematology and Pathology, University of Washington, Seattle, Washington 98104

hydrogen peroxide or a hydrogen peroxide-derived product mediates rapid nonlytic release of $\mathrm{PGI}_{2}$ from cultured endothelial cells.

\section{Introduction}

Since augmented neutrophil adherence to vascular endothelium is an early response to inflammation (1), neutrophils have been implicated in the pathogenesis of the altered vascular permeability associated with acute inflammation (2). The observation that neutrophil depletion attenuates permeability edema formation in several experimental models supports this hypothesis (3-5). Activated neutrophils have been shown to produce endothelial injury in vitro through the generation of toxic oxygen products $(6,7)$ and the release of granule proteases $(8)$. Since prostacyclin $\left(\mathrm{PGI}_{2}\right)^{1}$ has been demonstrated to have proinflammatory effects and to enhance edema formation (2, 9-16), we have examined the effect of activated neutrophils on endothelial $\mathrm{PGI}_{2}$ release by the use of purified human peripheral blood neutrophils, cultured bovine and human endothelial cells (ECs), and radioimmunoassay (RIA) and thin-layer chromatography (TLC) of 6-keto-prostaglandin $F_{1 \alpha}\left(6-k e t o-P G F_{1 \alpha}\right)$, the stable breakdown product of $\mathrm{PGI}_{2}$.

\section{Methods}

ECs. Bovine aortic and pulmonary artery and human umbilical vein ECs were prepared by collagenase treatment of vessels as previously described $(17,18)$ and maintained in $10 \%$ newborn calf serum (NBCS) (Gibco Laboratories, Gibco Div., Grand Island, NY) in Waymouth's medium (Gibco Laboratories, Gibco Div.). Bovine ECs were used in the 6th through the 15th passage. Individual experiments were performed with bovine ECs of the same strain and passage number. Human umbilical vein ECs were used in the first passage.

Preparation of neutrophils. Purified human peripheral blood neutrophils were prepared from heparinized blood from normal healthy donors by Ficoll-Hypaque (Pharmacia Fine Chemicals, Piscataway, NJ)

1. Abbreviations used in this paper: $\mathrm{EC}$, endothelial cell; NBCS, newborn calf serum; $\mathrm{PGE}_{1}, \mathrm{PGE}_{2}, \mathrm{PGF}_{1 \alpha}, \mathrm{PGF}_{2 \alpha}$, prostaglandins $\mathrm{E}_{1}, \mathrm{E}_{2}, \mathrm{~F}_{1 \alpha}$, $\mathrm{F}_{2 \alpha} ; \mathrm{PGI}_{2}$, prostacyclin; PMA, phorbol myristate acetate; RIA, radioimmunoassay; SBTI, soybean trypsin inhibitor; SOD, superoxide dismutase; TLC, thin-layer chromatography. 
gradient centrifugation and dextran sedimentation with hypotonic lysis of contaminating erythrocytes (19). Peripheral blood neutrophils were similarly prepared from blood obtained from a patient with chronic granulomatous disease and a patient with myeloperoxidase deficiency (courtesy of Dr. Henry Rosen, University of Washington, Seattle, WA). Neutrophils were suspended in Neuman-Tytell medium (Gibco Laboratories, Gibco Div.) at a concentration of $10^{7}$ cells $/ \mathrm{ml}$.

$R I A$ of EC 6-keto-PGF $F_{1 \alpha}$ release. ECs were plated at confluent density $\left(10^{5}\right.$ cells $\left./ \mathrm{cm}^{2}\right)$ in $10 \%$ NBCS in Waymouth's medium in $16-\mathrm{mm}$ or 23 mm wells (Cluster 3524 and 3512; Costar, Cambridge, MA) and allowed to adhere overnight. Before the experiment, monolayers were washed twice with serum-free Neuman-Tytell medium. The wash medium was then gently decanted and control or test agents or neutrophils in serumfree Neuman-Tytell medium were added. The monolayers were incubated at $37^{\circ} \mathrm{C}$ in $5 \% \mathrm{CO}_{2}$, and aliquots of cell-free supernatant medium were removed at intervals for determination of 6-keto-PGF $F_{1 \alpha}$. Cell counts were performed on replicate wells by electronic counter (Particle Data, Inc., Elmhurst, IL).

The measurement of unextracted, cell-free supernatant medium from the endothelial cultures for 6-keto-PGF ${ }_{1 \alpha}$ was performed in some samples by the determination of competitive inhibition of ${ }^{3} \mathrm{H}-6-k e t o-\mathrm{PGF}_{1 \alpha}$ to anti-6-keto-PGF $F_{1 \alpha}$ binding by the use of labeled tracers, standards, and antiserum from New England Nuclear (Boston, MA) (New England Nuclear Technical Bulletin NEK 008) (20). The standard curve range was 10 to $500 \mathrm{pg}$ added per $100 \mu \mathrm{l}$, with a normalized percent bound at $50 \%$ of $100-130 \mathrm{pg}$. Cross-reactivity of the 6-keto-PGF ${ }_{1 \alpha}$ antibody at a normalized percent bound of $50 \%$ was $\mathrm{PGF}_{1 \alpha}, 7.8 \%$; prostaglandin $\mathrm{E}_{1}\left(\mathrm{PGE}_{1}\right)$, 3\%; prostaglandin $\mathrm{F}_{2 \alpha}\left(\mathrm{PGF}_{2 \alpha}\right), 2.7 \%$; prostaglandin $\mathrm{E}_{2}\left(\mathrm{PGE}_{2}\right)$, $2 \%$; prostaglandin $A_{1},<0.3 \%$; prostaglandin $A_{2},<0.1 \%$; thromboxane $\mathrm{B}_{2},<0.1 \%$; and 13,14-dihydro-15 keto-PGF $\mathrm{PG}_{2 \alpha},<0.02 \%$ (New England Nuclear Technical Bulletin NEK-008). In other samples, 6-keto-PGF ${ }_{1 a}$ levels were determined by RIA with ${ }^{3} \mathrm{H}-6-$ keto-PGF $_{1 \alpha}$ (Amersham Corp., Arlington Heights, IL), authentic 6-keto-PGF ${ }_{1 \alpha}$ standard kindly provided by Douglas McCarter and Dr. John Pike (Upjohn Co., Kalamazoo, MI), and antiserum generously supplied by Dr. William B. Campbell, University of Texas Health Science Center at Dallas. This anti-6-keto-PGF $1 a$ antibody cross-reacted less than $0.9 \%$ with $\mathrm{PGE}_{1}, \mathrm{PGE}_{2}, \mathrm{PGF}_{1 \alpha}, \mathrm{PGF}_{2 \alpha}$, prostaglandin $D_{2}$, prostaglandin $A_{2}$, and thromboxane $B_{2}, 3.5 \%$ with

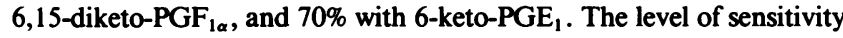
was $10 \mathrm{pg} / 300 \mu \mathrm{l}$. Assays were run in duplicate and at two dilutions when necessary. Results were confirmed in selected samples by inde-

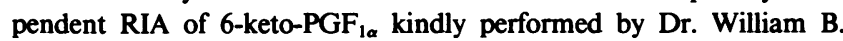
Campbell (21). Results obtained in the RIAs are expressed as picograms of 6-keto-PGF 1a $_{1 a}$ released per $10^{5}$ endothelial cells. For statistical calculations, samples with undetectable levels of 6-keto-PGF ${ }_{1 \alpha}$ were assumed to be equal to the lower limit of detection in the assay.

$T L C$ of bovine EC 6-keto-PGF $F_{1 \alpha}$ release. In some experiments, EC prostaglandin release was also assessed by TLC (22). EC lipids were labeled by the incubating of the cells for $6 \mathrm{~h}$ with $1.0 \mu \mathrm{Ci}\left[{ }^{3} \mathrm{H}\right]$ arachidonic acid (87.4 Ci/mmol, New England Nuclear) in Neuman-Tytell media. The cell monolayers were then washed three times with $10 \mathrm{mM}$ Hepes buffer (Gibco Laboratories, Gibco Div.) containing $0.15 \mathrm{M} \mathrm{NaCl}, 0.005$ $\mathrm{M} \mathrm{KCl}, 0.0018 \mathrm{M} \mathrm{CaCl}_{2}, 0.001 \mathrm{M} \mathrm{MgCl}_{2}$, glucose $1 \mathrm{~g} /$ liter, and fatty acid-free bovine serum albumin (Sigma Chemical Co., St. Louis, MO) to remove the unincorporated $\left[{ }^{3} \mathrm{H}\right]$ arachidonic acid. The monolayers were then incubated with control or test medium or agents. Cell-free supernatant medium was collected from each well after 30-60 min of incubation. The monolayers were then washed once with the Hepes buffer solution and the wash was pooled with the original supernatant medium.
The supernatant medium was acidified to pH 3.5 with glacial acetic acid and extracted twice with five times volume of ethyl acetate/cyclohexane (1:1). The organic layer was evaporated to dryness with nitrogen. Unlabeled 6-keto-PGF ${ }_{1 \alpha}$ and $\mathrm{PGE}_{2}$ (Sigma Chemical Co.) were added before extraction to localize these prostaglandins during chromatography. A small aliquot was also removed before and after extraction to correct for recovery. The dried residue was resuspended in $100 \mu$ l of ethyl acetate and applied to a $20 \times 20 \mathrm{~cm}$ silica gel 60 TLC plate (Merck and Co., Darmstadt, Germany). The plates were developed twice in a watersaturated mixture of ethyl acetate/glacial acetic acid/isooctane (110:20:50), and dried in air, and the spots were located with iodine vapor. Areas corresponding to 6-keto- $\mathrm{PGF}_{1 \alpha}, \mathrm{PGE}_{2}$, and arachidonic acid were then removed by scraping, extracted with chloroform/methanol (9:1), and dried under nitrogen, and scintillate was added for counting.

${ }^{51}$ Cr-release assay. ECs were plated on Microtest III plates (Falcon Labware, Div. Becton-Dickinson and Co., Oxnard, CA) and labeled with sodium $\left({ }^{51} \mathrm{Cr}\right)$ chromate (New England Nuclear) as previously described (8). After an overnight incubation, cells were washed three times with $1 \%$ NBCS in phosphate buffered saline (Gibco Laboratories, Gibco Div.) and then incubated with either test or control medium or cells. 50-100 $\mu \mathrm{l}$ of cell-free supernatant medium were removed at 4-6 h for determination of specific ${ }^{51} \mathrm{Cr}$ release by the formula $(A-B) /(C-B)$ $\times 100 \%$. $A$ represents the mean test ${ }^{51} \mathrm{Cr}$-counts per minute released, $B$ represents the mean spontaneous ${ }^{51} \mathrm{Cr}$-counts per minute released, and $C$ represents the mean maximum ${ }^{51} \mathrm{Cr}$-counts per minute released. Maximum ${ }^{51} \mathrm{Cr}$ release was determined by incubation in $1 \%$ Triton $\mathrm{X}-100$ (New England Nuclear). Spontaneous ${ }^{51} \mathrm{Cr}$ release was determined in control monolayers incubated in Neuman-Tytell medium only and was $5-10 \%$ of maximum ${ }^{51} \mathrm{Cr}$ release after $4 \mathrm{~h}$ of incubation. Statistical significance was determined by comparison of mean test and mean spontaneous ${ }^{51} \mathrm{Cr}$-counts per minute released by two-tailed, unpaired $t$ statistic.

Reagents. Acetylsalicylic acid, A23187, phorbol myristate acetate (PMA), soybean trypsin inhibitor (SBTI), mepacrine (quinacrine dihydrochloride), fatty acid-free albumin, catalase (bovine liver, 11,800 $\mathrm{U} / \mathrm{mg}$ ), superoxide dismutase (SOD) $(2,700 \mathrm{U} / \mathrm{mg}$ ), and glucose oxidase (grade VII) were obtained from Sigma Chemical Co. Sodium arachidonate was obtained from Bio/Data Corp. (Horsham, PA).

\section{Results}

Neutrophil-mediated bovine endothelial 6-keto- $P G F_{1 \alpha}$ release. Incubation of bovine EC monolayers with PMA alone or neutrophils alone did not induce significant release of 6-keto-PGF $F_{1 \alpha}$. When neutrophils were activated by PMA, however, a marked increase in 6-keto-PGF I $_{1 \alpha}$ release was noted. Because baseline (medium alone) and stimulated (arachidonic acid) release of 6-keto-PGF ${ }_{1 \alpha}$ from bovine EC monolayers varied considerably among strains and passage number in the same strain, results from individual experiments were expressed as the fold-increase in 6-keto-PGF $F_{1 \alpha}$ release (Table I). The increase in 6-keto-PGF $F_{1 \alpha}$ was due to release from ECs and not from neutrophils, since 6-keto-PGF ${ }_{1 \alpha}$ could not be detected when neutrophils were activated by PMA in the absence of ECs $\left(<100 \mathrm{pg} / 10^{7}\right.$ neutrophils in nine experiments).

Time course and dose response of neutrophil-mediated bovine $E C$ 6-keto- $P G F_{1 \alpha}$ release. Significant 6-keto-PGF ${ }_{1 \alpha}$ release was observed after a 15-min incubation of bovine EC monolayers 
Table I. Effect of PMA-activated Neutrophils on Bovine EC 6-keto-PGF $F_{1 \alpha}$ Release

\begin{tabular}{lc}
\hline $\begin{array}{l}\text { Addition to endothelial } \\
\text { monolayer }\end{array}$ & $\begin{array}{l}\text { Fold-increase in 6-keto } \\
\text { PGF } 1 \text { ra release }\end{array}$ \\
\hline PMA (4) & $1.1 \pm 0.7(P>0.05)$ \\
Neutrophils (4) & $1.1 \pm 0.5(P>0.05)$ \\
Neutrophils and PMA (18) & $12.2 \pm 1.5(P<0.001)$ \\
Arachidonic acid (6) & $35.1 \pm 3.8(P<0.001)$
\end{tabular}

Control medium, PMA (10 ng/ml), neutrophils (neutrophil-to-endothelial ratio of 10 to 1 ), neutrophils and PMA, or arachidonic acid $(50 \mu \mathrm{g} / \mathrm{ml})$ were added to bovine aortic or pulmonary artery EC monolayers. Aliquots of cell-free supernatant medium were removed after $30 \mathrm{~min}$ of incubation for determination of 6-keto-PGF ${ }_{1 \alpha}$ release by RIA. Values represent the mean $\pm 1 \mathrm{SE}$ of $(n)$ separate experiments. In each individual experiment the fold-increase in 6-ketoPGF $_{1 \alpha}$ release was determined from the mean of 2-4 replicate wells as (test - control)/control, where control represents mean 6-keto$\mathrm{PGF}_{1 \alpha}$ (picograms per $10^{5}$ cells) released with medium alone and test represents mean 6-keto-PGF $1 \alpha$ (picograms per $10^{5}$ cells) released after incubation with test agent or cell (i.e., PMA, neutrophils, PMA and neutrophils, or arachidonic acid). The $P$ value was determined by comparison of the mean value of 6-keto-PGF ${ }_{1 \alpha}$ released in control and test in each experiment by paired $t$ statistic.

with PMA-activated neutrophils (Figure $1 A$ ). Neutrophil-toendothelial ratios as low as 2 to 1 produced a significant increase in bovine endothelial 6-keto-PGF ${ }_{1 \alpha}$ release (Figure $1 B$ ).

Effect of inhibitors on neutrophil-mediated bovine endothelial 6-keto-PGF $F_{l \alpha}$ release. The effect of inhibitors on bovine endothelial 6-keto-PGF ${ }_{1 \alpha}$ release induced by PMA-activated neutrophils is summarized in Table II. Aspirin pretreatment of the bovine EC monolayers prevented neutrophil-mediated 6-ketoPGF $_{1 \alpha}$ release. SBTI, a potent inhibitor of neutrophil serine proteases, had no significant inhibitory effect. Superoxide dis-

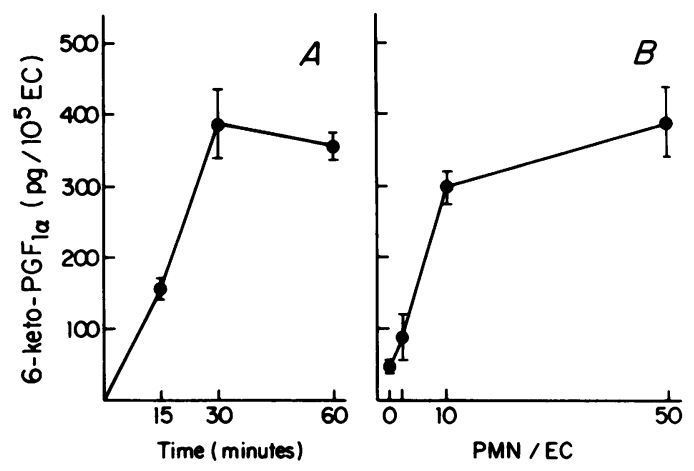

Figure 1. Time- and dose-response of neutrophil-mediated bovine EC 6-keto-PGF ${ }_{1 \alpha}$ release. PMA $(10 \mathrm{ng} / \mathrm{ml})$ and neutrophils $(\mathrm{PMN})$ were added to bovine aortic EC monolayers. In $A$, the neutrophil-to-endothelial ratio was 50 to 1 . In $B$, the incubation was $30 \mathrm{~min}$. Values represent mean $\pm 1 \mathrm{SE}$ of three replicate wells.
Table II. Effect of Inhibitors on Neutrophil-mediated Bovine EC 6-keto-PGF $F_{l \alpha}$ Release

\begin{tabular}{lll}
\hline $\begin{array}{l}\text { Addition to endothelial } \\
\text { monolayer }\end{array}$ & Inhibitor & $\begin{array}{l}\text { \% Inhibition of } \\
\text { endothelial 6-keto- } \\
\text { PGF 1a release }\end{array}$ \\
\hline PMA + neutrophils & Aspirin pretreatment (2) & 100 \\
& SBTI (2) & 0 \\
& SOD (6) & $6 \pm 2 \quad(P>0.05)$ \\
& Catalase (11) & $52 \pm 12(P=0.01)$ \\
& Catalase boiled (2) & 0 \\
A23187 & Catalase (1) & 0 \\
Arachidonic acid & Catalase (1) & 0 \\
\hline
\end{tabular}

Bovine endothelial 6-keto-PGF ${ }_{1 \alpha}$ release was determined by RIA of aliquots of cell-free supernatant medium after a 60 -min incubation with PMA (10 ng/ml)-activated neutrophils (neutrophil-to-endothelial ratio of 10 to 1) or a 30-min incubation with A23187 $(20 \mu \mathrm{M})$ or arachidonic acid $(50 \mu \mathrm{g} / \mathrm{ml})$. Aspirin pretreatment of EC monolayers was performed by incubating monolayers with aspirin $(1 \mathrm{mM})$ for 30 min and then washing with medium before the addition of PMA-activated neutrophils. Catalase $(3,000 \mathrm{U} / \mathrm{ml})$, catalase boiled for 10 $\mathrm{min}$, SOD $(270 \mathrm{U} / \mathrm{ml})$, and SBTI $(500 \mu \mathrm{g} / \mathrm{ml})$ were added simultaneously with the PMA-activated neutrophils. The percent inhibition $( \pm 1 \mathrm{SE})$ of endothelial 6-keto-PGF ${ }_{1 \alpha}$ release was calculated as the increase in endothelial 6-keto-PGF ${ }_{1 \alpha}$ release induced by PMA-activated neutrophils: ((without inhibitor - with inhibitor)/without inhibitor) $\times 100 \%$, where $(n)$ represents the number of individual experiments. In each individual experiment, values of 6-keto-PGF ${ }_{1 \alpha}$ were determined from the means of from two to four replicate wells. The $P$ value was determined by comparison of the mean fold-increase in 6keto-PGF ${ }_{1 \alpha}$ levels induced by PMA-activated neutrophils with inhibitor and without inhibitor in each experiment by paired $t$ statistic.

mutase also failed to prevent endothelial 6-keto-PGF ${ }_{1 \alpha}$ release. Catalase significantly reduced bovine endothelial 6-keto-PGF ${ }_{1 a}$ release induced by PMA-activated neutrophils, although the degree of inhibition varied somewhat between experiments (range, 30-95\%). Catalase did not inhibit endothelial 6-keto$\mathrm{PGF}_{1 \alpha}$ release induced by arachidonic acid or calcium ionophore.

Effect of PMA-activated chronic granulomatous disease neutrophils on bovine EC 6-keto-PGF $F_{1 \alpha}$ release. The inhibition of endothelial 6-keto-PGF $F_{1 \alpha}$ release after the addition of catalase to PMA-activated neutrophils suggested that hydrogen peroxide or a hydrogen peroxide-derived product was a critical mediator. To assess further the role of hydrogen peroxide, we examined the effect of PMA-activated neutrophils from a patient with chronic granulomatous disease and a patient with myeloperoxidase deficiency on endothelial 6-keto-PGF ${ }_{1 \alpha}$ release. Chronic granulomatous disease neutrophils, which do not generate hydrogen peroxide, failed to induce 6-keto-PGF ${ }_{1 \alpha}$ release when activated by PMA (Table III). Note that PMA-activated myeloperoxidase-deficient neutrophils, which produce hydrogen peroxide but not hypochlorous acid, induced 6-keto-PGF ${ }_{1 \alpha}$ re- 
Table III. Role of Oxygen Radicals in Bovine EC 6-keto-PGF $F_{1 \alpha}$ Release Induced by PMA-activated Neutrophils

\begin{tabular}{ll}
\hline Addition to endothelial monolayer & 6-keto-PGF 1 la \\
\hline & $p g / 10^{5} E C$ \\
Experiment 1 & \\
Normal neutrophils + PMA (3) & 247 \\
CGD neutrophils + PMA (3) & $<30$ \\
Experiment 2 & \\
Normal neutrophils + PMA (2) & 227 \\
CGD neutrophils + PMA (2) & $<30$ \\
\hline
\end{tabular}

In two separate experiments bovine aortic EC monolayers were incubated with normal or chronic granulomatous disease neutrophils (neutrophil-to-endothelial ratio of 10 to 1$)$ and PMA $(10 \mathrm{ng} / \mathrm{ml})$. After 60 min of incubation, an aliquot of cell-free supernatant medium was removed for determination of 6-keto-PGF $F_{1 \alpha}$ by RIA. Values represent means of $(n)$ replicate wells.

lease similar to that induced by normal neutrophils $(720 \pm 100$ $\mathrm{pg} / 10^{5}$ cells with normal PMA-activated neutrophils; $780 \pm 33$ $\mathrm{pg} / 10^{5}$ cells with myeloperoxidase-deficient PMA-activated neutrophils, mean \pm 1 SE of triplicate wells).

Effect of glucose-glucose oxidase on bovine endothelial 6-keto- $P G F_{1 \alpha}$ release. After the observations that endothelial 6-keto-PGF $F_{1 \alpha}$ release required a normal neutrophil oxidative burst and was catalase inhibitable, we examined the effect of a cell-free hydrogen peroxide-generating system, glucose-glucose oxidase, on bovine endothelial 6-keto-PGF P $_{1 \alpha}$ release. The addition of glucose-glucose oxidase to bovine EC monolayers produced significant catalase-inhibitable 6-keto- $\mathrm{PGF}_{1 \alpha}$ release (Table IV $A$ ). The boiling of glucose oxidase before its addition to the monolayer prevented 6-keto- $\mathrm{PGF}_{1 \alpha}$ release, and the boiling of catalase abolished its inhibitory effect, indicating that for both, enzymatic activity was required (Table IV $A$ ). Bovine EC 6keto-PGF ${ }_{1 \alpha}$ release induced by glucose-glucose oxidase was inhibited by the phospholipase inhibitor mepacrine (23) (Table IV $B$ ).

Effect of hydrogen peroxide on human EC 6-keto-PGF $F_{1} \alpha$ release. Because the bovine EC strains employed in these studies were multiply passaged, we were concerned that the effect of hydrogen peroxide on $\mathrm{PGI}_{2}$ release might be due to some alteration in arachidonic acid metabolism that occurred with prolonged passage. It is known, for example, that the amount of 6-keto-PGF - $_{1 \alpha}$ released from bovine aortic and pulmonary artery ECs after stimulation with ionophore or arachidonic acid decreases markedly with passage and that there is a shift from production of $\mathrm{PGI}_{2}$ to production of other prostanoids $(24,25)$. For this reason, we also examined the effect of hydrogen peroxide on first passage human umbilical vein ECs.

Both PMA-activated neutrophils and glucose-glucose oxidase induced dose-dependent release of 6-keto-PGF ${ }_{1 \alpha}$ from human umbilical vein ECs (Fig. 2). The amount of 6-keto-PGF ${ }_{1 \alpha}$ released
Table IV. Effect of Glucose-Glucose Oxidase on Bovine EC 6-keto-PGF $F_{1 \alpha}$ Release

\begin{tabular}{|c|c|}
\hline Addition to endothelial monolayer & 6-keto-PGF \\
\hline & $p g / 10^{5} E C$ \\
\hline \multicolumn{2}{|l|}{ A } \\
\hline Control medium (4) & $523 \pm 142$ \\
\hline Glucose oxidase (4) & $2,452 \pm 140$ \\
\hline Boiled glucose oxidase (4) & $404 \pm 95$ \\
\hline Glucose oxidase + catalase $(4)$ & $380 \pm 48$ \\
\hline Glucose oxidase + boiled catalase (4) & $1,714 \pm 333$ \\
\hline \multicolumn{2}{|l|}{ B } \\
\hline Control medium (3) & $105 \pm 7$ \\
\hline Glucose oxidase (3) & $2,410 \pm 540$ \\
\hline Glucose oxidase + mepacrine $(3)$ & $580 \pm 171$ \\
\hline
\end{tabular}

In $A$, glucose oxidase $(25 \mathrm{mU} / \mathrm{ml})$ or glucose oxidase boiled for 10 min with and without catalase $(3,000 \mathrm{U} / \mathrm{ml})$ or catalase boiled for 10 min were added to bovine aortic EC monolayers in Neuman-Tytell medium ( $22 \mathrm{mM}$ glucose). In $B$, monolayers were incubated with mepacrine $\left(10^{-4} \mathrm{M}\right)$ for $30 \mathrm{~min}$ before the addition of glucose oxidase $(10 \mathrm{mU} / \mathrm{ml})$. After $30 \mathrm{~min}$ of incubation, aliquots of cell-free supernatant medium were removed for determination of 6-keto-PGF $1 \alpha$ by RIA. Values represent mean $\pm 1 \mathrm{SE}$ of $(n)$ replicate wells.

after incubation of the first passage human umbilical vein ECs with PMA-activated neutrophils or the hydrogen peroxide-generating system were considerably greater than that observed
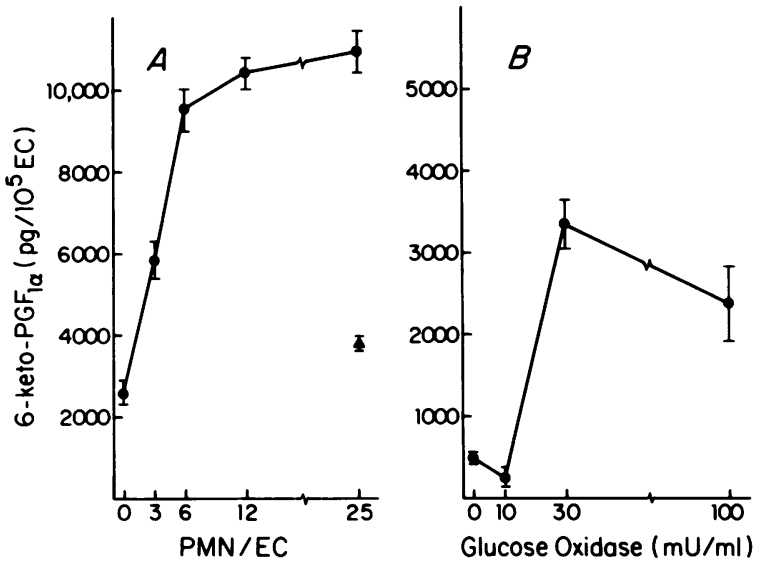

Figure 2. Hydrogen peroxide-mediated human umbilical vein EC 6-keto-PGF ${ }_{1 \alpha}$ release. In $A$, human EC monolayers were incubated in Neuman-Tytell medium (22 mM glucose) with or without PMA-activated neutrophils. Catalase $(3,000 \mathrm{U} / \mathrm{ml})$ (closed triangle) was added to the neutrophils before the addition of PMA. Aliquots of cell-free supernatant medium were removed at $\mathbf{3 0} \mathrm{min}$ for determination of 6-keto-PGF ${ }_{1 \alpha}$. Values represent mean $\pm 1 \mathrm{SE}$ of four replicate wells. In $B$, human EC monolayers were incubated in Neuman-Tytell medium with or without glucose oxidase. At $30 \mathrm{~min}$ aliquots of cell-free supernatant medium were removed for determination of 6-keto-PGF $1 \alpha$ by RIA. Values represent mean $\pm 1 \mathrm{SE}$ of three replicate wells. 
with the bovine cells. However, the levels of 6-keto-PGF ${ }_{1 \alpha}$ released by A23187 or arachidonic acid were likewise five- to tenfold greater in human cells than in bovine cells (data not shown). As with bovine ECs, the release of 6-keto-PGF Ia $_{1 \alpha}$ from the human ECs incubated with PMA-activated neutrophils (Fig. $2 A$ ) and with glucose-glucose oxidase (data not shown) was inhibited by catalase.

TLC of hydrogen peroxide-mediated EC 6-keto-PGF $F_{1 \alpha}$ release. The release of 6-keto-PGF $F_{1 \alpha}$ from ECs induced by neutrophil-derived and enzymatically generated hydrogen peroxide was confirmed by TLC. Table V $A$ demonstrates the catalaseinhibitable release of labeled 6-keto-PGF $\mathrm{PG}_{1 \alpha}, \mathrm{PGE}_{2}$, and arachidonic acid from prelabeled human EC monolayers incubated with PMA-activated neutrophils. Table V $B$ demonstrates the catalase-inhibitable release of these labeled products from prelabeled human EC monolayers incubated with glucose-glucose oxidase.

Relation of hydrogen peroxide-mediated endothelial 6-keto$P G F_{1 \alpha}$ release to cell lysis. The rapid release of 6-keto-PGF ${ }_{1 \alpha}$ from bovine EC monolayers during incubation with PMA-activated neutrophils was not correlated with EC lysis, as determined by ${ }^{51} \mathrm{Cr}$ release. Specific endothelial ${ }^{51} \mathrm{Cr}$ release was not observed even after a 4-h incubation of ${ }^{51} \mathrm{Cr}$-labeled EC monolayers with PMA-activated neutrophils (Table VI). PMA-activated neutrophils also failed to induce significant specific ${ }^{51} \mathrm{Cr}$ release from human EC monolayers at $4 \mathrm{~h}$ (data not shown).

Table $V$. TLC of $\mathrm{H}_{2} \mathrm{O}_{2}$-mediated

Human EC 6-Keto-PGF $F_{1 \alpha}$ Release

\begin{tabular}{|c|c|c|c|}
\hline \multirow[b]{2}{*}{$\begin{array}{l}\text { Addition to endothelial } \\
\text { monolayers }\end{array}$} & \multicolumn{3}{|c|}{${ }^{3} \mathrm{H}$-counts per minute released } \\
\hline & $\begin{array}{l}\text { 6-keto- } \\
\text { PGF }_{1 \alpha}\end{array}$ & $\mathrm{PGE}_{2}$ & Arachidonic acid \\
\hline \multicolumn{4}{|l|}{ A } \\
\hline Control medium & $38 \pm 4$ & $47 \pm 11$ & $1,112 \pm 340$ \\
\hline PMA + neutrophils & $267 \pm 85$ & $136 \pm 2$ & $5,772 \pm 248$ \\
\hline \multicolumn{4}{|l|}{ PMA + neutrophils } \\
\hline + catalase & $91 \pm 29$ & $80 \pm 14$ & $4,338 \pm 582$ \\
\hline \multicolumn{4}{|l|}{ B } \\
\hline Control medium & $93 \pm 9$ & $157 \pm 25$ & $6,293 \pm 481$ \\
\hline Glucose oxidase & $292 \pm 69$ & $385 \pm 108$ & $48,491 \pm 12,536$ \\
\hline \multicolumn{4}{|l|}{ Glucose oxidase } \\
\hline+ catalase & $102 \pm 28$ & $201 \pm 28$ & $4,597 \pm 284$ \\
\hline
\end{tabular}

In $A$, human umbilical vein EC monolayers were labeled with $\left[{ }^{3} \mathrm{H}\right]$ arachidonic acid, washed, and then incubated for $60 \mathrm{~min}$ with control medium, or PMA $(10 \mathrm{ng} / \mathrm{ml})$ and neutrophils (neutrophil-toendothelial cell ratio of 10 to 1$)$ with and without catalase (3000 U/ $\mathrm{ml})$. In $B$, control medium or glucose oxidase $(50 \mathrm{mU} / \mathrm{ml})$ with and without catalase $(3,000 \mathrm{U} / \mathrm{ml})$ were incubated for $30 \mathrm{~min}$ with $\left[{ }^{3} \mathrm{H}\right]$ arachidonic acid-labeled human umbilical vein EC monolayers. After incubation the cell-free supernatant medium was removed for determination of labeled 6-keto-PGF ${ }_{1 \alpha}, \mathrm{PGE}_{2}$, and arachidonic acid release by TLC. Values represent mean \pm 1 SD of duplicate wells.
Table VI. Effect of PMA-activated Neutrophils on Bovine EC Lysis

\begin{tabular}{lcl}
\hline & \multicolumn{2}{l}{ s'Cr release } \\
\cline { 2 - 3 } $\begin{array}{l}\text { Addition to endothelial } \\
\text { monolayers }\end{array}$ & cpm released & \% Specific release \\
\hline Control medium (8) & $234 \pm 15$ & \\
Neutrophils (8) & $195 \pm 8$ & 0 \\
PMA (8) & $236 \pm 20$ & 0 \\
PMA and neutrophils (8) & $249 \pm 18$ & $<1 \%$ \\
Triton X-100 (4) & $2,202 \pm 11$ & \\
\hline
\end{tabular}

Bovine aortic EC monolayers were labeled overnight with ${ }^{51} \mathrm{Cr}$, washed, and then incubated with control medium, neutrophils (neutrophil to endothelial ratio of 10 to 1$),$ PMA $(10 \mathrm{ng} / \mathrm{ml})$, neutrophils and PMA, or Triton X-100 (0.1\%). After $4 \mathrm{~h}$ an aliquot of cell-free supernatant medium was removed for determination of ${ }^{51} \mathrm{Cr}$ release. Values represent mean \pm 1 SE of $(n)$ replicates.

\section{Discussion}

The acute inflammatory response is characterized by neutrophil adherence to endothelium and neutrophil accumulation at the inflammatory site (1). The vascular response to neutrophil infiltration includes an increase in local blood flow and altered vascular permeability, resulting in edema formation. Numerous studies have implicated prostaglandins, particularly $\mathrm{PGE}_{2}$ and $\mathrm{PGI}_{2}$, as critical mediators of the hyperemia and increased permeability that accompany the neutrophil infiltration (2, 9-16). Because the vascular endothelium releases $\mathrm{PGI}_{2}$ and $\mathrm{PGE}_{2}$ when stimulated (26), ECs are a potential source for the local production of these prostaglandins during the acute inflammatory response.

Our studies demonstrate that PMA-activated human peripheral blood neutrophils induce a time- and dose-dependent release of $\mathrm{PGI}_{2}$ from cultured ECs. Since PMA does not induce the release of arachidonic acid metabolites from human neutrophils (27), and aspirin pretreatment of the endothelium prevented 6-keto-PGF ${ }_{1 \alpha}$ release, it is unlikely that endothelial $\mathrm{PGI}_{2}$ release occurs as a result of the provision of a substrate for endothelial cyclooxygenase by neutrophil-generated endoperoxides, as has been described for platelet-endothelial interactions (28). The failure of PMA to induce arachidonic acid release in human neutrophils also suggests that neutrophil lipoxygenase products are not involved in $\mathrm{EC} \mathrm{PGI}_{2}$ release by neutrophils stimulated with PMA. Since leukotrienes $\mathrm{C}_{4}$ and $\mathrm{D}_{4}$ have been demonstrated to induce endothelial $\mathrm{PGI}_{2}$ synthesis (29), it is possible that neutrophil-activating agents that result in leukotriene production could provoke endothelial $\mathrm{PGI}_{2}$ release through generation of leukotriene $C_{4}$ or $D_{4}$.

Because neutral proteases such as trypsin and thrombin have been demonstrated to stimulate endothelial $\mathrm{PGI}_{2}$ release (30), neutrophil-derived neutral proteases such as elastase and cathepsin $G$ might be expected to mediate endothelial 6-keto- 
$\mathrm{PGF}_{1 \alpha}$ release. Several factors, however, suggest that neutrophilderived neutral proteases are not involved in the 6-keto-PGF release induced by PMA-activated neutrophils. First, at the concentration of PMA $(10 \mathrm{ng} / \mathrm{ml})$ and time course (15-30 min) used in these studies, there is minimal release of the neutrophil azurophilic granules that contain the neutral proteases (31). Second, SBTI, a potent serine protease inhibitor, did not prevent 6-keto-PGF ${ }_{1 \alpha}$ release induced by PMA-activated neutrophils. Finally, purified elastase and cathepsin $G$ do not directly affect baseline endothelial $\mathrm{PGI}_{1 \alpha}$ release (32).

The failure of PMA-activated neutrophils from a patient with chronic granulomatous disease to induce endothelial $\mathbf{P G I}_{2}$ release indicates that an oxygen radical is involved. Since catalase, but not superoxide dismutase, significantly reduces 6-keto-PGF 1 a release from ECs incubated with PMA-activated neutrophils, it appears that hydrogen peroxide or a hydrogen peroxide-derived product is the critical neutrophil-generated mediator. This is supported by the observation that the hydrogen peroxide-generating system, glucose-glucose oxidase, can also induce catalaseinhibitable $\mathrm{PGI}_{2}$ release from cultured ECs over the same time course. Catalase did not always completely inhibit neutrophilmediated $\mathbf{P G I}_{2}$ release, whereas it totally prevented glucoseglucose oxidase-mediated release; this may be due to exclusion of this enzyme at sites where neutrophils and ECs adhere closely.

Our observation that peroxide-stimulated prostaglandin generation by ECs is not associated with cellular lysis has also been recently reported by Ager and Gordon (33). These investigators found that porcine aortic endothelium synthesized $\mathrm{PGI}_{2}$ and $\mathrm{PGE}_{2}$ in response to enzymatically generated hydrogen peroxide at a concentration significantly lower than that which was lethal to the cells.

The results obtained by TLC confirm those obtained by RIA. The TLC results demonstrate that enzymatically or neutrophil-generated hydrogen peroxide induces the release of labeled arachidonic acid, 6-keto-PGF $1 \alpha$, and $\mathrm{PGE}_{2}$ from prelabeled endothelial cells. Hydrogen peroxide has been observed to induce $\mathrm{PGE}_{2}$ release from fibroblasts, and an organic peroxide has been reported to induce $\mathrm{PGI}_{2}$ release from $\operatorname{ECs}(34,35)$. The inhibition of hydrogen peroxide-induced endothelial $\mathrm{PGI}_{2}$ release by the phospholipase inhibitor mepacrine (23) suggests that hydrogen peroxide may act by triggering membrane phospholipase $A_{2}$, thus liberating arachidonic acid as a substrate for cyclooxygenase.

The conversion of the arachidonic acid released by the exogenously generated hydrogen peroxide to $\mathrm{PGI}_{2}$ is a cyclooxygenase-catalyzed event, since it is inhibited by aspirin. The reported effects of peroxides on the cyclooxygenase-dependent conversion are variable. Peroxides have been observed to both activate $(36,37)$ and inactivate cyclooxygenase $(38)$. Since hydroperoxides can inactivate endothelial $\mathrm{PGI}_{2}$ synthetase (39), peroxides may also affect the subsequent conversion of the endoperoxides generated by cyclooxygenase. If cyclooxygenase is stimulated while $\mathrm{PGI}_{2}$ synthetase is inhibited, enhanced synthesis of $\mathrm{PGE}_{2}$ may occur (40).

The effects of exogenously generated peroxides on endothelial arachidonic acid metabolism may be critically dose dependent.
Taylor et al. noted that high concentrations of hydroperoxides inhibited 6-keto-PGF $F_{1 \alpha}$ production in bovine ECs and $\mathrm{PGE}_{2}$ in fibroblasts, whereas low concentrations stimulated prostaglandin release (35). Hydrogen peroxide-induced endothelial prostaglandin production may thus be a net result of complex stimulatory and inhibitory effects on the various enzyme systems involved.

The observation that exogenously generated hydrogen peroxide can induce the release of $\mathrm{PGI}_{2}$ from cultured ECs is of particular interest in acute inflammation where the endothelium may be exposed to hydrogen peroxide generated by inflammatory cells such as neutrophils and monocytes. The release of a potent vasodilator such as $\mathrm{PGI}_{2}$ may augment local edema formation (2, 9-16). Alternatively, the release of $\mathrm{PGI}_{2}$ could prevent the adherence and activation of additional inflammatory cells by elevating intracellular cyclic AMP (41-44). The demonstration that a toxic oxygen radical generated by one cell can trigger the release of arachidonic acid metabolites by another cell further illustrates the possibilities for interactions between inflammatory mediators.

\section{Acknowledgments}

We are grateful to Kathe Stanness for her technical assistance.

This work was supported by grants HL18645, GM29853, and HL07312 from the U. S. Public Health Service and by a grant from R. J. Reynolds Industries, Inc. (Winston-Salem, NC). It was performed during the tenure of a Clinician Scientist Award of the American Heart Association to Dr. Harlan, with funds contributed in part by the American Heart Association of Washington.

\section{References}

1. Grant, L. 1973. The sticking and emigration of white blood cells in inflammation. In The Inflammatory Process. B. W. Zweifach, L. Grant, and R. T. McCluskey, editors. Academic Press Inc., New York. Vol II. 205-249.

2. Wedmore, C. V., and T. J. Williams. 1981. Control of vascular permeability by polymorphonuclear leukocytes in inflammation. Nature (Lond.). 289:646-650.

3. Heflin, A. C. Jr., and K. L. Brigham. 1981. Prevention by granulocyte depletion of increased vascular permeability of sheep lung following endotoxemia. J. Clin. Invest. 65:1253-1260.

4. Flick, M. R., A. Perel, and N. C. Staub. 1981. Leukocytes are required for increased lung microvascular permeability after microembolization in sheep. Circ. Res. 48:344-351.

5. Johnson, A., and A. B. Malik. 1980. Effect of granulocytopenia on extravascular lung water content after microembolization. Am. Rev. Respir. Dis. 122:561-566.

6. Sacks, T., C. F. Moldow, P. R. Craddock, T. K. Bowers, and H. S. Jacob. 1978. Oxygen radicals mediate endothelial cell damage by complement-stimulated granulocytes. An in vitro model of immune vascular damage. J. Clin. Invest. 61:1161-1167.

7. Weiss, S. J., J. Young, A. F. LoBuglio, A. Slivka, and N. F. Nimeh. 1981. Role of hydrogen peroxide in neutrophil-mediated destruction of cultured endothelial cells. J. Clin. Invest. 68:714-721.

8. Harlan, J. M., P. D. Killen, L. A. Harker, and G. E. Striker. 1981. 
Neutrophil-mediated endothelial injury in vitro. Mechanisms of cell detachment. J. Clin. Invest. 68:1394-1403.

9. Williams, T. J., and J. Morley. 1973. Prostaglandins as potentiators of increased vascular permeability in inflammation. Nature (Lond.). 246:215-217.

10. Williams, T. J., and M. J. Peck. 1977. Role of prostaglandinmediated vasodilatation in inflammation. Nature (Lond.). 270:530-532.

11. Higgs, E. A., S. Moncada, and J. R. Vane. 1978. Inflammatory effects of prostacyclin $\left(\mathrm{PGI}_{2}\right)$ and 6-oxo-PGF ${ }_{1 \alpha}$ in the rat paw. Prostaglandins. 16:153-162.

12. Ford-Hutchinson, W. A., J. R. Walker, E. M. Davidson, and M. J. Smith. 1978. PGI $_{2}$ : a potential mediator of inflammation. Prostaglandins. 16:253-259.

13. Mullane, K. M., and S. Moncada. 1980. Prostacyclin release and the modulation of some vasoactive hormones. Prostaglandins. 20:25-49.

14. Komoriya, K., H. Ohmori, A. Azuma, S. Kurozumi, Y. Hashimoto, K. C. Nikolaou, W. E. Barnette, and R. L. Magolda. 1978. Prostaglandin $I_{2}$ as a potentiator of acute inflammation in rats. Prostaglandins. 15:557-564.

15. Issekutz, A. C. 1981. Vascular responses during acute neutrophilic inflammation. Their relationship to in vivo neutrophil emigration. Lab. Invest. 45:435-441.

16. Higgs, G. A., and J. A. Salmon. 1979. Cyclo-oxygenase products in carrageenin-induced inflammation. Prostaglandins. 17:737-745.

17. Wall, R. T., L. A. Harker, L. J. Quadracci, and G. E. Striker. 1978. Factors influencing endothelial cell proliferation in vitro. J. Cell Physiol. 96:203-213.

18. Schwartz, S. M. 1978. Selection and characterization of bovine aortic endothelial cells. In Vitro. 14:966-980.

19. Boyum, A. 1968. Isolation of mononuclear cells and granulocytes from human blood. Isolation of mononuclear cells by one centrifugation, and of granulocytes by combining centrifugation and sedimentation at one g. Scand. J. Clin. Lab. Invest. 21(Suppl. 97):77-89.

20. Harlan, J. M., L. A. Harker, G. E. Striker, and L. J. Weaver. 1983. Effects of lipopolysaccharide on human endothelial cells in culture. Thromb. Res. 29:14-26.

21. Hirsh, P. D., L. D. Hillis, W. B. Campbell, B. G. Firth, and J. T. Willerson. 1981. Release of prostaglandins and thromboxane into the coronary circulation in patients with ischemic heart disease. $N$. Engl. J. Med. 304:685-691.

22. Alhenc-Gelas, F., S. J. Tsai, K. S. Callahan, W. B. Campbell, and A. R. Johnson. 1982. Stimulation of prostaglandin formation by vasoactive mediators in cultured human endothelial cells. Prostaglandins. 24:723-742.

23. Hirata, F., B. A. Corcoran, K. Venkatasubramanian, E. Schiffmann, and J. Axelrod. 1979. Chemoattractants stimulate degradation of methylated phospholipids and release of arachidonic acid in rabbit leukocytes. Proc. Natl. Acad. Sci. USA. 76:2640-2643.

24. Goldsmith, J. C., C. T. Jafvert, P. Lollar, W. G. Owen, and J. C. Hoak. 1981. Prostacyclin release from cultured and ex vivo bovine vascular endothelium. Studies with thrombin, arachidonic acid, and ionophore A23187. Lab. Invest. 45:191-197.

25. Goldsmith, J. C., and S. W. Needleman. 1982. A comparative study of thromboxane and prostacyclin release from ex vivo and cultured bovine vascular endothelium. Prostaglandins. 24:173-178.

26. Weksler, B. B., A. J. Marcus, and E. A. Jaffe. 1977. Synthesis of prostaglandin $I_{2}$ (prostacyclin) by cultured human and bovine endothelial cells. Proc. Natl. Acad. Sci. USA. 74:3922-3926.

27. Walsh, C. E., B. M. Waite, M. J. Thomas, and L. R. DeChatelet. 1981. Release and metabolism of arachidonic acid in human neutrophils. J. Biol. Chem. 256:7228-7234.

28. Marcus, A. J., B. B. Weksler, E. A. Jaffe, and M. J. Broekman. 1980. Synthesis of prostacyclin from platelet-derived endoperoxides by cultured human endothelial cells. J. Clin. Invest. 66:979-986.

29. Benjamin, C. W., N. K. Hopkins, T. D. Oglesby, and R. R. Gorman. 1983. Agonist specific desensitization of leukotriene $\mathrm{C}_{4}$-stimulated $\mathrm{PGI}_{2}$ biosynthesis in human endothelial cells. Biochem. Biophys. Res. Comm. 117:780-787.

30. Weksler, B. B., C. W. Ley, and E. A. Jaffe. 1978. Stimulation of endothelial cell prostacyclin production by thrombin, trypsin, and the ionophore A23187. J. Clin. Invest. 62:923-930.

31. Wright, D. G., D. A. Bralove, and J. I. Gallin. 1977. The differential mobilization of human neutrophil granules. Effects of phorbol myristate acetate and ionophore A23187. Am. J. Pathol. 87:237-284.

32. Weksler, B. B., M. Brower, R. deRoque, E. A. Jaffe, and K. Tack-Goldman. 1982. Alterations in endothelial cell function induced by proteases from human polymorphonuclear leukocytes. Blood. 60:255a. (Abstr.)

33. Ager, A., and J. L. Gordon. 1984. Differential effects of hydrogen peroxide on indices of endothelial cell function. J. Exp. Med. 159:592603.

34. Polgar, P., and L. Taylor. 1980. Stimulation of prostaglandin synthesis by ascorbic acid via hydrogen peroxide formation. Prostaglandins. 19:693-700.

35. Taylor, L., M. J. Menconi, and P. Polgar. 1983. The participation of hydroperoxides and oxygen radicals in the control of prostaglandin synthesis. J. Biol. Chem. 258:6855-6857.

36. Hemler, M. E., H. W. Cook, and W. E. Lands. 1979. Prostaglandin biosynthesis can be triggered by lipid peroxides. Arch. Biochem. Biophys. 193:340-345.

37. Hemler, M. E., and W. E. Lands. 1980. Evidence for a peroxideinitiated free radical mechanism of prostaglandin biosynthesis. J. Biol. Chem. 255:6253-6261.

38. Egan, R. W., J. Paxton, and F. A. Kuehl, Jr. 1976. Mechanism for irreversible self-deactivation of prostaglandin synthetase. J. Biol. Chem. 251:7329-7335.

39. Weiss, S. J., J. Turk, and P. Needleman. 1979. A mechanism for the hydroperoxide-mediated inactivation of prostacyclin synthetase. Blood. 53:1191-1196.

40. Kent, R. S., S. L. Diedrich, and A. R. Whorton. 1983. Regulation of vascular prostaglandin synthesis by metabolites of arachidonic acid in perfused rabbit aorta. J. Clin. Invest. 72:455-465.

41. Moncada, S. 1982. Prostacyclin and arterial wall biology. Arteriosclerosis. 2:193-207.

42. Gorman, R. R., S. Bunting, and O. V. Miller. 1977. Modulation of human platelet adenylate cyclase by prostacyclin (PGX). Prostaglandins. 13:377-388.

43. Tateson, J. E., S. Moncada, and J. R. Vane. 1977. Effects of prostacyclin (PGX) on cyclic AMP concentrations in human platelets. Prostaglandins. 13:389-397.

44. Boxer, L. A., J. M. Allen, M. Schmidt, M. Yoder, and R. L. Baehner. 1980. Inhibition of polymorphonuclear leukocyte adherence by prostacyclin. J. Lab. Clin. Med. 95:672-678. 